\title{
Clinical Improvement in Patients with Morbus Hansen Borderline Tuberculoid Lesions with 3-Month Multibacillary Regimen Therapy
}

\author{
Putu Eka Ratna Setia Rahayu ${ }^{1}$, Gusti Ayu Vina Mery Giovani² \\ ${ }^{1}$ General Practitioner at Siloam Hospital in Badung, Bali, Indonesia, 80361 \\ ${ }^{2}$ Dermatology and Venerology Specialist at Siloam Hospital in Badung, Bali, Indonesia, 80361 \\ Corresponding Author: Putu Eka Ratna Setia Rahayu
}

DOI: https://doi.org/10.52403/ijrr.20220129

\begin{abstract}
Background/Aim: Morbus Hansen $(\mathrm{MH})$ is a chronic infectious disease caused by Mycobacterium leprae. The disease has an average incubation period of 3-5 years. Morbus Hansen (MH) has various clinical, microbiological and histopathological features. In the following, a new case of $\mathrm{MH}$ is reported with a clinical manifestation of Borderline Tuberculoid (BT) type MH. The patient was treated with the MDT MB regimen for 3 months and had clinical improvement.

Case Report: A 23-year-old boy with complaints of sudden feeling of heat, tingling and cramping from the tip of his right foot to the sole of his right foot. He also complaining about black lesions on both hands, right elbow, face, chest and back. The diagnosis of gout, fungus and dermatitis can be ruled out after microscopic examination of AFB on the right, left ear lobe, and foot lesions showed negative results and histopathological examination results showed Morbus Hansen type BT. The risk factor for contracting Morbus Hansen is the patient has lived in a dormitory for 2.5 years and it is known that there are people who suffer from a similar disease in that environment. The patient was treated using a multibacillary regimen for 3 months and the lesions improved and the numbness decreased. Treatment plan during the case for 12-18 months. This case is unique due to the clinical manifestation has not significant characteristic for $\mathrm{MH}$, AFB is not found from ear lobe smear. MH established after skin biopsy done.
\end{abstract}

Conclusion: It was reported that one $\mathrm{MH}$ case with TB for 3 months had clinical improvement, with plans to continue treatment for 12-18 months.

Keywords: Borderline Tuberculoid; Morbus Hansen, Multibacillary

\section{INTRODUCTION}

Morbus Hansen, also known as leprosy, is a chronic infection caused by Mycobacterium leprae, this disease attacks the peripheral nerves and skin. Morbus Hansen has been known since 3000 years ago and is thought to have originated in Asia or Africa. WHO data in 2017 shows that Indonesia is one of the 3 countries in the world with the most new cases of leprosy. India, Brazil and Indonesia accounted for $80.2 \%$ of new leprosy cases in the world. During 2015-2017, there were 3,373 new cases in East Java, 1,813 new cases in West Java, 1,644 in Central Java and 1,091 in South Sulawesi.[1]

In 2013 based on the report of the Directorate General (Directorate General) of Disease Control and Environmental Health of the Ministry of Health of the Republic of Indonesia, the highest prevalence of leprosy cases was reported from East Java Province at 4132 cases, followed by West Java at 2,180 cases, and Papua at 1765 cases. Based on these data, it was found that the province with the highest proportion of leprosy was 
Putu Eka Ratna Setia Rahayu et.al. Clinical improvement in patients with morbus Hansen borderline tuberculoid lesions with 3-month multibacillary regimen therapy.

male from East Java (23.25\%), West Java $(13.5 \%)$, and Central Java (10.82\%).[2]

M. leprae attacks Schwann cells in peripheral nerves and macrophages in skin and other organs. M. leprae does not produce toxins, but affects host cell immunity in expressing bacterial antigens. The $\mathrm{T}$ helper (Th) 1 immune response causes activation of $\mathrm{T}$ lymphocytes and chronic inflammatory granulomas in peripheral nerves, skin and other organs, resulting in various tissue damage and functional disorders, whereas the Th2 immune response triggers humoral immunity such as the production of ineffective antibodies to kill intracellular germs. so that $\mathrm{M}$. leprae replicates in host cells. The entrance of $\mathrm{M}$. leprae into the human body is mainly through the respiratory tract and to a lesser extent through unintacted skin. M. leprae enters the host's body, will settle in Schwann cells or macrophages.[3]

It is not known with certainty the mode of transmission of Morbus Hansen, only people with cell-mediated immunity disorders specific to M. leprae will have symptoms. People who have a strong immune system and are infected with $\mathrm{M}$. leprae will develop tuberculoid leprosy (TT) with a single lesion and no bacilli are found, while people who do not have cell-mediated immunity will develop lepromatous leprosy (LL) where the appearance of infiltrated skin M. leprae contains histiocyte cells that contain leprosy bacilli. Between TT and LL are borderline tuberculoid (BT), mid borderline (BB), and borderline lepromatous (BL) which are found in people with low cell-mediated immunity and an increased number of bacilli.[4]

The Borderline Tuberculoid (BT) type has lesions resembling the TT type, in the form of macules or plaques that are often accompanied by satellite lesions on the cheeks. The number of lesions may be single or multiple, but the appearance of hypopigmentation, skin dryness, or scaling is not as clear as the tuberculoid type. Noncaseating granulomas are less pronounced and nerve damage is less prominent. Acidfast bacilli are often absent. Nerve disorders are less severe than the tuberculoid type, and are usually asymmetrical. The tubercle development is slow and consists of lymphocytes surrounding the neurovascular bundle and infiltration of the salivary glands and erector pili. Langhans datia cells vary in number and are not large in size. Granulomas are usually in the superficial vascular plexus but do not infiltrate into the epidermis.[5-7]

The diagnosis of $\mathrm{MH}$ is made when at least one cardinal sign is found, including: numb skin patches, thickening of the peripheral nerves, with or without pain and impaired function of the affected nerves, and acid-fast bacteria are found on examination of ear lobe smears and skin lesions on the earlobes. In the following, a new case of $\mathrm{MH}$ is reported with a clinical picture of Borderline Tuberculoid (BT) type MH.[1,6] The patient was treated with the MDT MB regimen for 3 months due to more than 5 lesions according to WHO 2017.[8] After therapy, the patient experienced clinical improvement. The purpose of this case report is to provide information that there is clinical improvement in Borderline Tuberculoid (BT) type MH with multibacillary therapy.

\section{CASE REPORT}

A 23-year-old adult male came to hospital. Initially the patient felt heat in his right leg and then felt numb and black lesions appeared on the right foot, both hands, right elbow on the face, chest and back. The patient checked his complaint to a dermatologist. On physical examination, his vital signs and general status were within normal limits, a solitary hyperpigmented macular lesion was found with dry erosions on it and the edema, loss of sensory (heat, tactile) on the lesions (right foot, both hands, right elbow, chest, back and face), the motor of the right toe I and II of the right toe decreased. Lesions wheat they first appear shows hyperpigmentation in plantar foot in figure 1. Lesions before therapy 
Putu Eka Ratna Setia Rahayu et.al. Clinical improvement in patients with morbus Hansen borderline tuberculoid lesions with 3-month multibacillary regimen therapy.

(after 3 months complaints) in figure 2 showing hiperpygmentation and black lesions appeared.

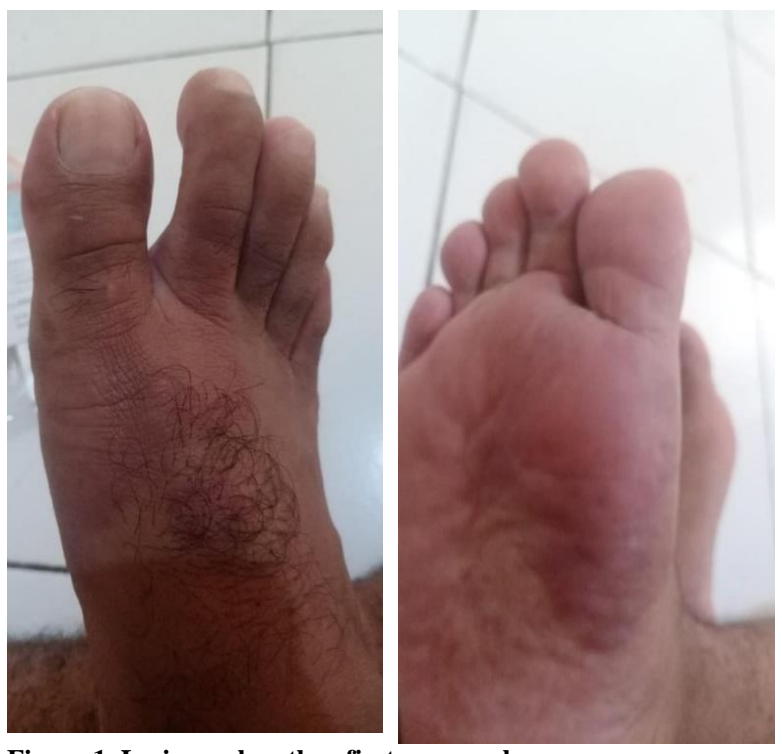

Figure 1. Lesions when they first appear shows

hyperpigmentation in plantar foot

Family history of disease is unknown. The patient's previous history was that he had lived in a pesantren for 2.5 years, the last patient lived in a pesantren in 2018.

Patient underwent a microscopic examination of AFB in the area of the right and left ear lobes, which reveal negative AFB. Then was proceed histopathological examination, which shows granulomas consisting of epithelioid cells, and lymphoid, sudoriferous glands appear. However, in Ziehl-Nelseen staining, acidfast bacilli (BTA) were not found. Based on these finding, the diagnosis of Morbus Hansen type BT was established. Patient was treated with:

Day 1: 2 capsules of rifampicin $(2 \times 300$ $\mathrm{mg}), 3$ capsules of clofazimine $(3 \times 100$ $\mathrm{mg}), 1$ tablet of dapsone ( 1 x $100 \mathrm{mg}$ )

Days 2-28: 1 capsule of clofazimine (50 $\mathrm{mg}$ ) and 1 capsule of dapsone $(100 \mathrm{mg}$ ).

In addition to the multibacillary regimen, the patient was also treated with vitamins $\mathrm{B} 1, \mathrm{~B} 6$ and $\mathrm{B} 12$.
The patient received therapy in September 2021. On physical examination, after 3 months of walking therapy, on physical examination of the right foot, a solitary hyperpigmented macular lesion was found with dry erosions on it and the edema of the lesion was much reduced. Lesions on the right elbow, both hands, face, chest and back showed hyperpigmented macules with punch out lesions (Figure 3-5). On physical examination, the motor of the right toe I and II of the right toe decreased, the patient had difficulty lifting the first and second toes of the right toe. Hyposthesia is present in the lesion of the right foot and right elbow, lesions in the right and left antebrachii as well as on the chest and back can feel tactile stimulation, heat and pain. There is no enlargement of the median and auricular nerves, there is no mucosal disorder (no eye complaints).

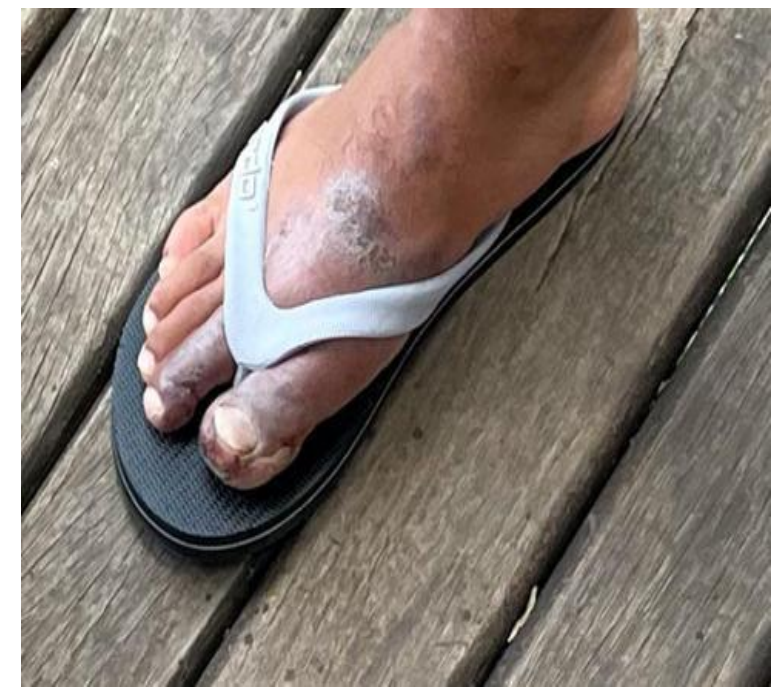

Figure 2. Lesions before therapy (after 3 months complaints)

Patients and families were given consultation, information, and education (IEC) regarding the disease and the results of supporting examinations, the therapy given and the plan for administering MDT as many as 6 packages, the importance of medication adherence, possible side effects of drugs, and routine control. 
Putu Eka Ratna Setia Rahayu et.al. Clinical improvement in patients with morbus Hansen borderline tuberculoid lesions with 3-month multibacillary regimen therapy.
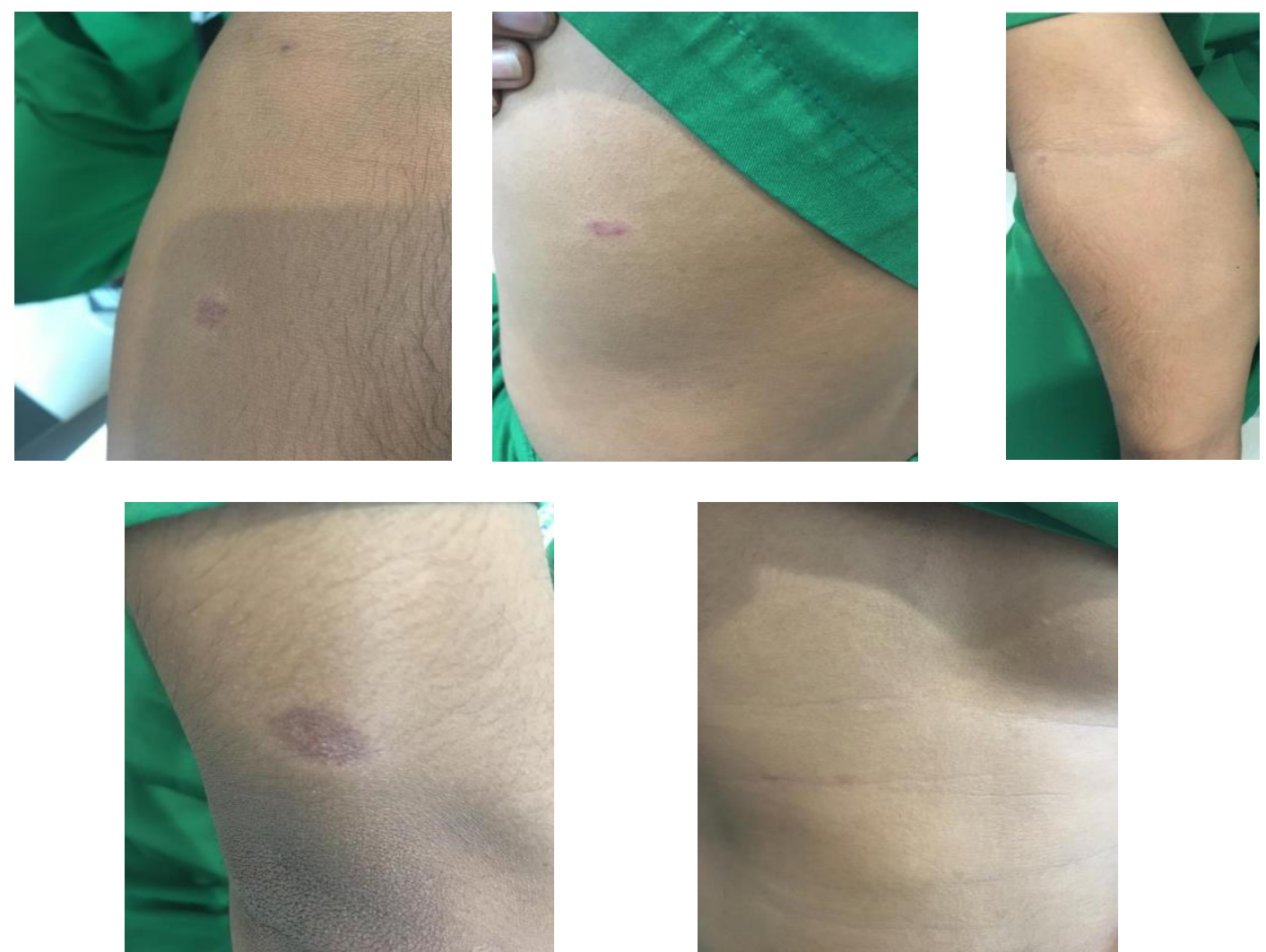

Figure 3. Lesions on both hands, right elbow back, chest after 3 months of therapy

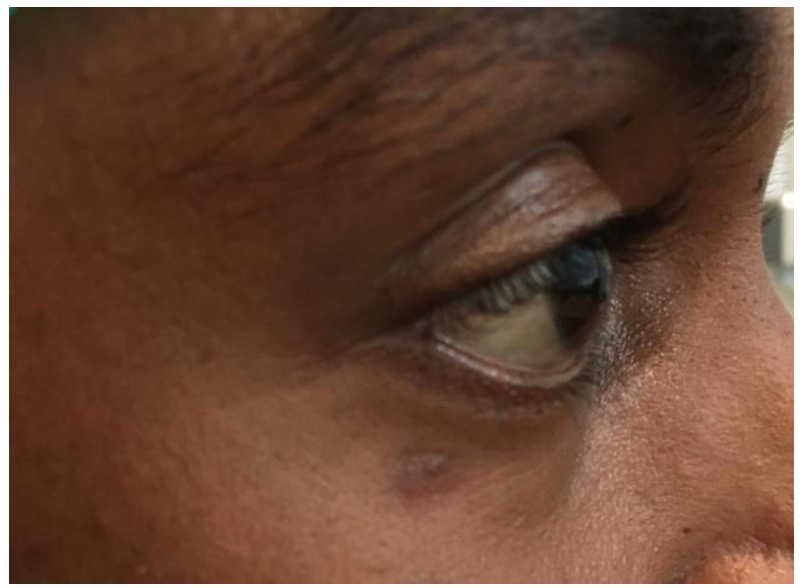

Figure 4. Lesions on the face after 3 months of therapy

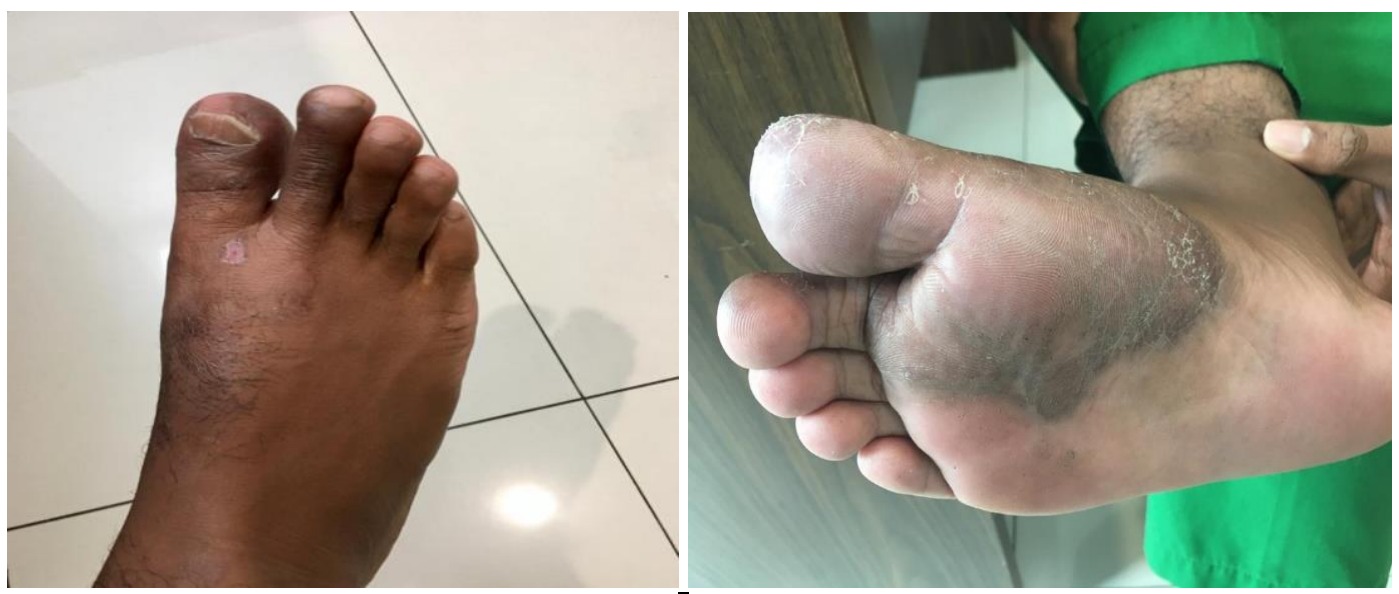

Figure 5. Lesions after 3 months therapy 
Putu Eka Ratna Setia Rahayu et.al. Clinical improvement in patients with morbus hansen borderline tuberculoid lesions with 3-month multibacillary regimen therapy.

\section{DISCUSSION}

Morbus Hansen is a chronic granulomatous disease that attacks the skin and nerves caused by the obligate intracellular pathogen Mycobacterium leprae. This disease in addition to attacking the skin and nerves can cause sequelae (sequelae) in other wider tissues such as the eyes, upper respiratory tract, lymphoid tissue, testes, muscles and bones. The diagnosis is made on the basis of signs and symptoms, including loss of sensation in the skin, pain or swelling of the nerves or a microscopic smear for bacilli and a skin biopsy.[7]

Morbus Hansen $(\mathrm{MH})$ can occur at any age, but most are at the age of 20-30 years, followed by the age of 60-70 years. The study of Moorthy BN et al (2001) found that the majority of $\mathrm{MH}$ patients were aged between 20-29 years, which was $20.70 \%$. Children under 9 years of age are the least affected by $\mathrm{MH}$, which is $6.45 \%$. Most countries in the world except for a few countries in Africa find that men are more affected by $\mathrm{MH}$ than women. This may be influenced by environmental and sociocultural factors. In certain cultures, women's access to health services is very limited, so they are not detected.[5] In this case the patient is a male and 23 years old.

Symptoms of Morbus Hansen attack the skin, nerves and mucous membranes, skin symptoms such as changes in skin color, usually flat and appear lighter in color than the surrounding skin, then grow into nodules, the skin becomes thickened, stiff and dry until a painless ulcer can appear (usually occurs on the soles of the feet), other skin symptoms include swelling or mass on the face and earlobe, loss of hair in the eyes and eyebrows. Symptoms of Morbus Hansen affecting the nerves include numbness in the affected skin, muscle weakness or paralysis (especially in the feet and hands), enlarged nerves (especially in the elbow and knee areas and in both necks), eye problems that can cause blindness (when attack the facial nerve). Symptoms of Morbus Hansen that attack the mucus glands include an enlarged nose and nosebleeds.[9]

In this case, a picture/photo of the lesion appeared at the beginning of the appearance of symptoms in the form of a hyperpigmented macula accompanied by heat and numbness sensation in the right leg (figure 1), then the patient had not been treated and the lesion developed into hyperpigmented plaques, the skin looked thickened and dry. When the patient received a multibacillary regimen, the lesion was characterized by reduced thickening of solitary hyperpigmented macules with overlying dry erosions and markedly reduced edema of the lesion. Lesions on the right arm, left, face, chest and back showed hyperpigmented macules with punch out lesions. On physical examination, the motor toes I and II were reduced, sensory examination was not felt in the lesions on the right foot and right elbow. While the sensory examination of the bilateral antebrachial lesions, the chest and back were back to normal.

The typical histopathological picture of BT is epithelioid granuloma in the dermis that partially touches the basal layer of the epidermis, foamy macrophages, datia langhans cells and lymphocyte inflammatory cells are found, and no Grenz zone picture is found.[10] The RidleyJopling classification is based on clinical, histopathological and immunological features, which are widely accepted by histopathologists and leproologists. The difference between clinical and histopathological diagnosis may arise because the clinical picture shows the overall morphology of the lesion caused by the underlying pathology, whereas the histopathological picture shows the tissue response microscopically and is more accurate.[11] Various factors can influence the histopathological diagnosis, including differences in sample size, location of the lesion being biopsied, age of the lesion, immunological status and treatment of the patient at the time of biopsy.[12] The ideal type of MH cannot be determined solely by 
Putu Eka Ratna Setia Rahayu et.al. Clinical improvement in patients with morbus Hansen borderline tuberculoid lesions with 3-month multibacillary regimen therapy.

clinical features or histopathological parameters alone. Correlation of clinical and histopathological features along with bacteriological indices is more useful for determining the exact type of $\mathrm{MH}$ than considering only one parameter.[13] If a discrepancy is found between clinical and histopathological diagnosis, the patient is diagnosed and treated according to the more severe type of $\mathrm{MH}$, i.e. toward the lepromatous pole to prevent inadequate treatment.[13] In this case the patient received a 12-18 month MDT MB therapy regimen and experienced clinical improvement.

In 2017, WHO revised the Morbus Hansen Pausi- bacillary and Multibacillary case definitions as follows:

Pausibacillary: cases with skin lesions 1-5 without finding bacilli in the skin lesion smear.

Multibacillary: Cases with more than 5 skin lesions; or with neurological symptoms (neuritis alone, or skin lesions followed by neuritis); or the presence of bacilli in a smear of skin lesions regardless of the number of lesions.[7]

In this case there were more than 5 skin lesions, there was neuritis, no acid-fast bacilli were found, the skin lesion smear and histopathological examination showed an image in accordance with Borderline Tuberculoid and on Ziehl-Nelseen staining no acid-fast bacilli (AFB) were found. . In this case, it is concluded that this case is a multibacillary case with Borderline Tuberculoid type. The patient was treated with a red blister regimen for multibacillary. The multibacillary therapy regimens obtained were:

Day 1: 2 capsules of rifampicin (2 x 300 $\mathrm{mg}), 3$ capsules of clofazimine $(3 \times 100$ $\mathrm{mg}), 1$ tablet of dapsone $(1 \times 100 \mathrm{mg})$

Days 2-28: 1 capsule of clofazimine (50 $\mathrm{mg}$ ) and 1 capsule of dapsone $(100 \mathrm{mg}$ ).

The main objectives of the $\mathrm{MH}$ control program are early detection of patients to break the chain of transmission and reduce the incidence of disease, appropriate management, prevention of disability and rehabilitation.10 For the purposes of MH therapy with MDT, WHO divides $\mathrm{MH}$ into paucibacillary (PB) type with negative smear and multibacillary (MB) with positive smear.[14] MDT is a combination of two or more anti-leprosy drugs. Groups of patients who need MDT include new patients diagnosed with leprosy and have never received MDT, patients experiencing relapse, default, transferred patients, and changing classifications. The MDT treatment regimen for adult PB type MH patients in 1 package consisted of rifampin $600 \mathrm{mg}$ taken once a month under supervision and dapsone $100 \mathrm{mg}$ per day taken alone. The duration of treatment is as much as 6 packages which are spent in a period of 6 to 9 months.[13]

Psychosocial problems are more common in patients who suffer from $\mathrm{MH}$ because it takes a long time to recover, giving rise to psychosocial problems in the patient's life. Social stigma in leprosy makes the condition of psychosocial development and behavior of the sufferer worse. When a person is diagnosed with leprosy, his normal psychological condition is affected. Negative reactions from family, friends, and community exacerbated his already declining morale and overall psychological state. In this case, the patient received $\mathrm{MH}$ from the dormitory he lived in, so that the patient with $\mathrm{MH}$ had a feeling of fear of transmitting the leprosy he suffered to his family and friends around him. The term "social" has a very broad meaning. The meaning of social in the dictionary is living in groups, one does not lead a solitary life. The social process or socialization is a lifelong phenomenon. It starts in the family and continues through school, contact with family, friends, co-workers. The term social and economic reintegration is intended to make people with leprosy return to their original social and economic status, or to bring them back to their role in society so that they can live a good normal life, where this can be achieved through rehabilitation measures.[13-15] So that in this case, explanations are still given to the family and 
Putu Eka Ratna Setia Rahayu et.al. Clinical improvement in patients with morbus Hansen borderline tuberculoid lesions with 3-month multibacillary regimen therapy.

the patient directly regarding the illness and its treatment, even though within 3 months it has shown clinical improvement results and the tingling race must still be evaluated further.

\section{CONCLUSION}

A case of $\mathrm{MH}$ was reported clinically and histopathologically in the form of $\mathrm{MH}$ type BT in a 23-year-old man received an MDT MB therapy regimen for 12-18 months and experienced clinical improvement with reduced edema and numbness after 3 months.

\section{Competing Interests}

No competing interests were disclosed.

\section{Conflict of Interest}

The authors declare no conflict of interest, financial or otherwise.

\section{Acknowledgements}

Declared none.

Patients' Consent: The patient has given permission and informed consent for the publication of this case report.

\section{REFERENCES}

1. Alinda MD, Geani S, Agusni RI, Kusumaputra BH, Reza NR, Prakoeswa CRS, et al. Diagnosis and Management of Leprosy. Berk Science of Skin and Sexual Health. 2020;32(2):149.

2. Director General of $\mathrm{P} 2 \mathrm{P}$ of the Indonesian Ministry of Health. Action Plan For Disease Prevention And Control Program 2015-2019 ( Revision I - 2018 ). 2015-2019 P2P Program ACTION Plan. 2019;2019:86.

3. Eichelmann K, González González SE, Salas-Alanis JC, Ocampo-Candiani J. Leprosy. An Update: Definition, Pathogenesis, Classification, Diagnosis, and Treatment. Actas DermoSifiliográficas (English Ed. 2013;104(7):554-63.
4. Bhat RM, Prakash C. Leprosy: An overview of pathophysiology. Interdiscip Perspect Infect Dis. 2012;2012.

5. Mayasari R, R S. Clinical Diagnosis of Morbus Hansen Type Mid Borderline (BB) with Histopathological Appearance of Morbus Hansen Type Borderline Tuberculoid (BT). J Medical Doctor of Public Health Science Faculty of Medicine Sriwij Univ. 2019;6(2):5762.

6. Fischer M. Leprosy - an overview of clinical features, diagnosis, and treatment. JDDG - J Ger Soc Dermatology. 2017;15(8):801-27.

7. Cooreman E, Gillini L, Pemmaraju V, Shridar M, Tisocki K, Ahmed J, et al. Guidelines for the diagnosis, treatment and prevention of leprosy. WorldHealing Organs. 2018;1:106.

8. WHO. Evolution of WHO air quality guidelines. Copenhagen: WHO Regional Office for Europe. 2017.

9. Salvador JFS, Mendaza FH, Garcés MH, Palacios-Martínez D, Camacho RS, Sanz RS, et al. Guidelines for the Diagnosis, Treatment, and Prevention of Hand Eczema. Actas Dermosifiliogr. 2020;(October).

10. Nurhadi S. Morbus Hansen Borderline Tuberculoid Type with Leprosy Grade 2. 2016;

11. Lowell A. Goldsmith, Stephen I. Katz, Barbara A. Gilchrest, Amy S. Paller, David J. Lefflell KW. Fitzpatric's Dermatology in General Medicine. 8th ed. New York: McGraw-Hill Education; 2015.

12. Kundakci N, Erdem C. Leprosy: A great imitator. Clin Dermatol. 2019;37(3):200-12.

13. Maymone MBC, Venkatesh S, Laughter M, Abdat R, Hugh J, Dacso MM, et al. Leprosy: Treatment and management of complications. J Am Academy Dermatol. 2020;83(1):17-30.

14. Andini F, Warganegara E, Medicine F, Lampung U. Morbus Hansen Multibacillary Type with Type 1 
Putu Eka Ratna Setia Rahayu et.al. Clinical improvement in patients with morbus Hansen borderline tuberculoid lesions with 3-month multibacillary regimen therapy.

Leprosy Reaction and Grade 2 Disability Multibacillary Hansen's Disease with Type 1 Reaction and Grade 2 Disability. J Unila medulla. 2016; 6(1):44-9.

15. Gunawan HC. Getting to know Morbus Hansen Alumni Profile Prof . Dr. dr. L. Meily K., M. Sc, Sp. OK Dr. Amrita Devi, Msi, SpKJ Various Events on How to cite this article: Putu Eka Ratna Setia Rahayu, Gusti Ayu Vina Mery Giovani. Clinical improvement in patients with morbus Hansen borderline tuberculoid lesions with 3-month multibacillary regimen therapy. International Journal of Research and Review. 2022; 9(1): 231-238. DOI: https://doi.org/10.52403/ijrr.20220129

(March):0-32. 